\title{
New strategies of diagnostic and therapeutic approach to emergencies in the evolution of patients with diabetes mellitus (Review)
}

\author{
MARIA FORȚOFOIU ${ }^{1 *}$, IONELA MIHAELA VLADU ${ }^{2 *}$, MIRCEA-CĂTĂLIN FORȚOFOIU $^{3}$, \\ RODICA PĂDUREANU ${ }^{4}$, DIANA CLENCIU ${ }^{2 *}$, DUMITRU RĂDULESCU ${ }^{5}$ and VLAD PĂDUREANU ${ }^{3}$ \\ Departments of ${ }^{1}$ Emergency, ${ }^{2}$ Diabetes and Nutritional Diseases, and ${ }^{3}$ Internal Medicine, Faculty of Medicine, \\ University of Medicine and Pharmacy of Craiova, 200349 Craiova; ${ }^{4}$ Department of Internal Medicine, \\ Emergency Clinical County Hospital of Craiova, 200642 Craiova; ${ }^{5}$ Department of Surgery, \\ University of Medicine and Pharmacy of Craiova, 200349 Craiova, Romania
}

Received September 29, 2021; Accepted October 29, 2021

DOI: $10.3892 /$ etm.2021.11101

\begin{abstract}
Diabetes mellitus, known as the most widespread disease in the world, along with four other chronic diseases, involves major expenditures and significant human resources for care, thus representing a burden on any type of health care system especially due to its rapid evolution of acute and chronic complications. For the emergency department (ED), the requirements of patients with acute complications of diabetes, determine expenses which are three times higher than those for non-diabetic patients and their hospitalizations are four times more frequent. The acute complications for which patients with diabetes most frequently require the ED are hypoglycemic, hyperosmolar, or ketoacidosis coma as well as alterations of the general condition that is typical of hypoglycemia, diabetic ketoacidosis (DKA), hyperglycemic hyperosmolar state and new-onset hyperglycemia. Hypoglycemia and the Somogyi phenomenon are the most common complications of type 1 diabetes but they can also occur in patients with type 2 diabetes who are treated with insulin through its overdose. DKA can occur in type 1 and 2 diabetes either by administering inadequate
\end{abstract}

Correspondence to: Professor Mircea-Cătălin Forțofoiu, Department of Internal Medicine, Faculty of Medicine, University of Medicine and Pharmacy of Craiova, 2 Petru Rareș Str., 200349 Craiova, Romania E-mail: catalin.fortofoiu@umfcv.ro

Dr Rodica Pădureanu, Department of Internal Medicine, Emergency Clinical County Hospital of Craiova, 1 Tabaci Str., 200642 Craiova, Romania

E-mail: zegheanurodica@yahoo.com

${ }^{*}$ Contributed equally

Key words: diabetic coma, diabetic emergencies, hypoglycemia, diabetic ketoacidosis, hyperglycemic hyperosmolar state, emergency therapy doses of insulin or due to the existence of precipitating factors such as stress, acute myocardial infarction, infections, sepsis, and/or gastrointestinal bleeding. Hyperosmolar hyperglycemic status is the most common complication in patients with type 2 diabetes and DKA. Treating the acute complications of diabetes in the ED involves, besides taking immediate measures to assess and maintain vital functions, monitoring patients, assessing blood sugar, electrolytes, urea, creatinine, and bicarbonate, and applying appropriate immediate therapeutic measures for each type of acute diabetes complication.
Contents
1. Introduction
2. Diabetic ketoacidosis
3. Hyperglycemic hyperosmolar state
4. Hypoglycemia
5. Conclusions

\section{Introduction}

Diabetic ketoacidosis (DKA) and hypoglycemia are the most common diabetes emergencies that can occur in a hospital emergency department (ED) (1). Along with these, less common, hyperglycemic hyperosmolar state (HHS) is associated with unpredictable evolution and increased risk of mortality. DKA and HHS are biochemically different conditions that require different approaches to treatment depending on the precipitating factor. Optimal treatment requires the involvement of a multidisciplinary team. The disorder can have significant mortality in the absence of early diagnosis and treatment instituted.

In recent years, DKA management has changed, the diagnosis is made only when all three components are present (' $\mathrm{D}=$ diabetes', ' $\mathrm{K}=$ ketosis' and 'A = acidosis'). In addition, constant monitoring of the level of plasma ketones is crucial. 
Table I. Classification of DKA.

DKA

\begin{tabular}{lcccc}
\cline { 3 - 4 } Factors & Normal & Mild & Moderate & Severe \\
\hline Arterial $\mathrm{pH}$ & $7.35-7.45$ & $7.25-7.30$ & $7.00-7.24$ & $<7.00$ \\
Serum bicarbonate $(\mathrm{mEq} / \mathrm{l})$ & $22-28$ & $15-18$ & $10-14$ & $<10$ \\
Serum/urine ketone & Absent & Present & Present & Present \\
Glucose level (mg/dl) & $70-110$ & $>250$ & $>250$ & $>250$ \\
Effective serum osmolarity & $275-295$ & Variable & Variable & Variable \\
Anion gap & $<11$ & $>10$ & $>12$ & $>12$ \\
Mental status & Normal & Alert & Alert/drowsy & Stupor/coma \\
\hline
\end{tabular}

Adapted from ref. 4. Arterial pH, serum bicarbonate, serum/urine ketonase, glucose level, effective serum osmolarity, anion gap, mental status.

Instead, for HHS the first therapeutic step is the rehydration of the patient, followed by initiation of insulin treatment, as a means of decreasing glucose levels.

In the present review, we performed a literature search in the PubMed and Scopus databases using the key words, 'diabetic coma', in combination with 'diabetic emergencies' and 'hypoglycemia' and 'diabetic ketoacidosis' and 'hyperglycemic hyperosmolar state' and 'emergency therapy' between 1990 and 2020. Relevant articles and reviews regarding the new strategies of diagnostic and therapeutic approach to emergencies in the evolution of patients with diabetes mellitus were included. Exclusion criteria included studies written in languages other than English, letters to the editor, conference presentations, editorials, comments, opinions and articles without free access.

\section{Diabetic ketoacidosis}

Features of DKA. The main features of DKA are hyperglycemia, metabolic acidosis with a high anion gap and heavy ketonuria. The usual features of DKA include hyperglycemia $(>250 \mathrm{md} / \mathrm{dl})$, metabolic acidosis $(\mathrm{pH}<7.35$ and bicarbonate $<15 \mathrm{mmol} / \mathrm{l})$, high anion gap and ketonemia/heavy (3+) ketonuria (2).

This contrasts with the other hyperglycemic diabetic emergency of hyperosmolar non-ketonic hyperglycemia where there is no acidosis, absent or minimal ketonuria but often extremely high glucose levels ( $>33 \mathrm{mmol} / \mathrm{l})$ and very high serum sodium levels (>150 mmol/l) (3).

DKA precipitating factors. Factors to consider for type 1 diabetes (absolute insulin deficiency) include: inaugural coronary artery disease; discontinuation of insulin treatment (intentional, limited access to health care services, and technical defects in insulin delivery devices such as pens and insulin pumps); associated acute conditions (e.g., surgery, stroke, acute myocardial infarction, infections and trauma) that increase the level of counterregulatory hormones (catecholamines, cortisol and glucagon) (4). Factors to consider for type 2 diabetes (relative insulin deficiency) include: associated acute conditions (e.g., surgery, stroke, myocardial infarction, infections and trauma).
Diagnostic criteria and classification of DKA. DKA is a complex state of metabolic disorders defined by the American Diabetes Association (ADA) as severe hyperglycemia (plasma glucose levels $>250 \mathrm{mg} / \mathrm{dl}$, ketonemia (ketosis) and metabolic acidosis ( $\mathrm{pH}<7.3$; serum bicarbonate $<18 \mathrm{mmol} / \mathrm{l}$ ) (Table I). Depending on the severity, in 2009, the ADA classified DKA as mild, moderate and severe (5).

In 2013, the Joint British Diabetes Societies Inpatient (JBDS IP) Group DKA Guidelines introduced serum ketone (3-beta-hydroxybutyrate [pHBA]) into the definition of DKA, although pHBA measurement for the diagnosis and monitoring of DKA was recommended in the ADA Diabetes Laboratory Guidelines in 2011 (5-8) The markers by which the severity of DKA can be quantified are depicted in Table II.

Treatment of DKA. The overall aims in the treatment of DKA are to improve circulatory volume and tissue perfusion, decrease blood glucose, and correct the acidosis and electrolyte imbalances. The administration of low-dose insulin $(0.1 \mathrm{U} / \mathrm{kg} / \mathrm{h})$ and intravenous fluid and electrolyte replacement solutions may contribute to these objectives (9). Frequent monitoring of serum glucose, venous $\mathrm{pH}$ and $\mathrm{pHBA}$ is required. It is important to identify and treat the cause that triggered DKA, the infection being often the most common trigger of DKA.

The essential elements that must be provided to patients with DKA include fluids, insulin, potassium and education. Early venous approach and urinary catheterization are also required, especially if the patient is hemodynamically unstable or requires accurate measurement of diuresis.

Hydration. If the patient is not in shock or oliguric, hydration is provided by administering $500 \mathrm{ml} / \mathrm{h}$ of $0.9 \%$ saline for $4 \mathrm{~h}$, followed by $250 \mathrm{ml} / \mathrm{h}$ for the next $4 \mathrm{~h}$. Simultaneous correction of acidosis and hyperglycemia should be performed at the same time as hydration. Excess fluid should not be given as there is a risk of cerebral edema. The most commonly used hydration solution is saline ( $0.9 \%$ ), although no adverse effects have been reported with $0.45 \%$ saline or Ringer's solution $(1,2)$. Volume recovery can be clinically quantified by measuring the heart rate and $\mathrm{BP}$, diuresis, urea dosage, and serum creatinine. 
Table II. Markers of severity in DKA.

\begin{tabular}{ll}
\hline Variable & \\
\hline Marker of severity & JBDS IP Group 2013 \\
Mental status & GCS $<12$ or abnormal AVPU \\
Oxygen saturation & $<92 \%$ on air (assuming normal baseline respiratory function) \\
Venous/arterial pH & $\mathrm{pH}<7.1$ \\
Potassium & $\mathrm{Hypokalemia}(<3.5 \mathrm{mmol} / \mathrm{l})$ or hyperkalemia $(>6 \mathrm{mmol} / \mathrm{l})$ \\
Systolic blood pressure & $<90 \mathrm{mmHg}$ \\
Pulse & $>100 \mathrm{or}<60 \mathrm{bpm}$ \\
Urine output & $<0.5 \mathrm{ml} / \mathrm{kg} / \mathrm{h}$ or other evidence of AKI \\
Blood ketones & $>6 \mathrm{mmol} / 1$ \\
Bicarbonate level & $<5 \mathrm{mmol} / \mathrm{l}$ \\
Anion gap sodium & $>16 \mathrm{mmol} / \mathrm{l}$ \\
\hline
\end{tabular}

Adapted from ref. 5. Equivalent to $>12 \mathrm{mEq} / \mathrm{l}$ for the USA anion gap calculation; the USA equation does not add [K+] to [Na+] before subtracting anions. DKA, diabetic ketoacidosis. AKI, acute kidney injury; GCS, Glasgow Coma Scale; AVPU, alert, voice, pain, unresponsive scale.

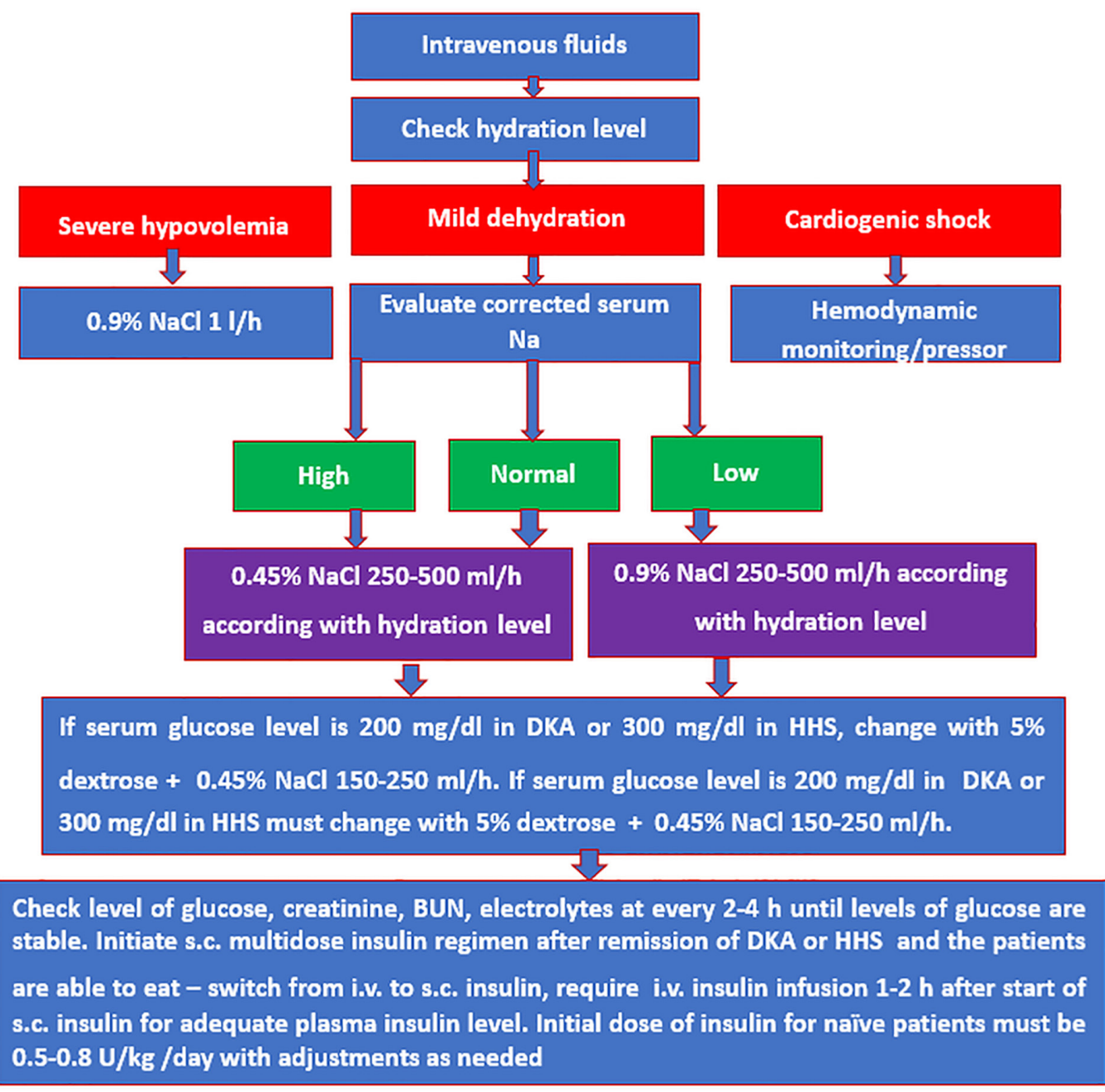

Figure 1. Management of fluids and further steps in type 2 diabetes mellitus complications (adapted from refs. 11,21).

After the serum glucose level has dropped $<250 \mathrm{mg} / \mathrm{dl}$, $5 \%$ dextrose (with adequate potassium) may be introduced into the infusion regimen rather than saline. Administering hypertonic dextrose (1 liter 10\% dextrose +40 units insulin at $250 \mathrm{ml} / \mathrm{h}$ ) rather than isotonic dextrose (1 liter 5\% dextrose +10 units insulin at $250 \mathrm{ml} / \mathrm{h}$ ) may accelerate the clearance of ketone bodies but also causes a rise in glucose levels without additional improvement in blood pH or bicarbonate (9) (Fig. 1). 
Insulin. A soluble fast-acting insulin is used to reduce high serum blood glucose levels, even if there is no evidence that the use of insulin analogues increases the risk of DKA.

The insulin level is reached very quickly when an intravenous bolus is followed by an intravenous infusion. The half-life of circulating insulin is $5 \mathrm{~min}$. The administration of an intravenous infusion has the advantage that it allows a more rapid reduction of the insulin level compared to the administration of intermittent bolus (8).

Usually, a bolus of 6 units is used followed by an infusion of $6 \mathrm{U} / \mathrm{h}$ at the beginning of the treatment in the case of an adult with DKA (usually for a patient weighing $<60 \mathrm{~kg}$, $0.1 \mathrm{U} / \mathrm{kg}$ are used). When there is a severe drop in blood sugar levels, a sudden change in the osmolality of the extracellular fluid can occur, which can cause cerebral edema (5).

Lack of therapeutic response, in the absence of a mechanical cause, raises the suspicion of a present infection or insufficient hydration. In this case, the dose of insulin that should be increased or even doubled should be reconsidered.

Ketone bodies are cleared more slowly than glucose during DKA treatment. The mean duration of treatment until blood glucose is $<250 \mathrm{mg} / \mathrm{dl}(\sim 14 \mathrm{mmol} / \mathrm{l})$ and ketoacidosis ( $\mathrm{pH}>7.30$; bicarbonate $>18 \mathrm{mmol} / \mathrm{l}$ ) is corrected, is between 6 and 12 h, respectively (10).

Insulin infusion is required until the disappearance of ketone bodies and the subsequent correction of acidosis. Otherwise, discontinuation of the insulin infusion once the glycemic level is normalized may result in a recurrence of ketoacidosis, unless hypertonic dextrose is used in the infusion. Subcutaneous administration of insulin should be initiated prior to stopping the insulin infusion, preferably in the morning.

For the treatment of type 1 diabetes, continuous infusions of subcutaneous insulin are commonly used in continental Europe with an increasing use in the UK (10). This type of treatment was initially associated with an increased risk of DKA due to equipment failure (11); however, as this equipment was improved, this high risk of DKA decreased.

Potassium level $(K)$. Subsequent to the administration of insulin, potassium enters the cells, and there is a risk of hypokalemia, the most common electrolyte disorder that can endanger the life of a patient. Therefore, intravenous potassium administration is absolutely necessary with insulin. Potassium administration before initiating insulin therapy is not indicated, as it may result in an increase in the extracellular level of potassium (12).

Potassium administration is recommended to be initiated at the same time as insulin and fluid start, even if the potassium level is within normal limits. The appropriate potassium replacement regimen (11) should adhere to the following rules: start $\mathrm{KCl}$ when $\mathrm{K}$ is normal or low with an average dose of $20 \mathrm{mmol} / \mathrm{h}$, but if initially $\mathrm{K}$ is increased, $\mathrm{KCl}$ administration should be delayed until levels decrease to within normal range (Fig. 2). In DKA, it is essential to administer potassium in order to avoid cardiovascular complications due to hypokalemia, hyperkalemia or HHS (12).

Bicarbonate. In clinical trials and in practice, bicarbonate administration in DKA has not been shown to be useful in the clinical and biochemical recovery of patients and it is even associated with delayed disappearance of ketone bodies and

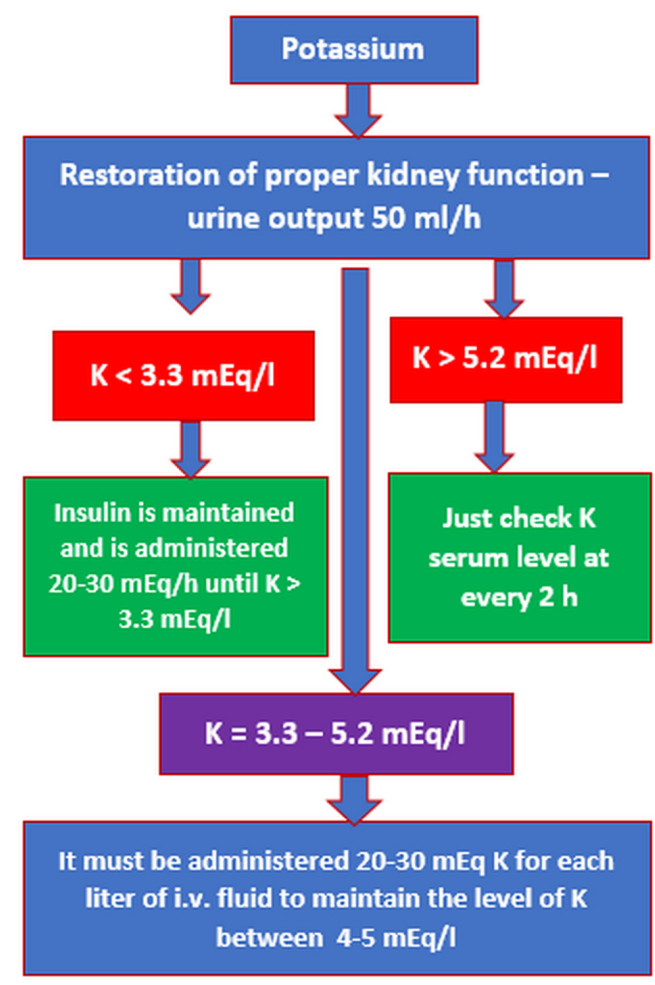

Figure 2. Management of potassium in acute complications of diabetes mellitus (adapted from refs. 11,21).

lactate levels. In addition, bicarbonate can depress cardiac activity, and increase intravascular volume at risk of pulmonary edema as it is hypertonic and hyperosmolar (12-16).

It is recognized that an increase in $\mathrm{pH}$ is associated with a shift to the left in the $\mathrm{Hb}-\mathrm{O}_{2}$ dissociation curve, leading to a decrease of tissue oxygenation as well as an increase in the lactate production. $\mathrm{P}_{\mathrm{a}} \mathrm{CO}_{2}$ rises due to bicarbonate infusion. In addition, intracellular acidosis can be exacerbated by the rapid diffusion across cell membranes. This phenomenon is more serious especially in situations when the patient is unable to compensate by increasing $\mathrm{CO}_{2}$ excretion $(14,15)$.

During the recovery period of DKA, lactate produced during tissue hypoxia is metabolized to bicarbonate, leading to alkalosis $(17,18)$. The correction of the bicarbonate level that appears in the DKA must be carried out under permanent $\mathrm{pH}$ control, to ensure optimal insulin treatment (Fig. 3).

Phosphate. In DKA, phosphate levels are altered in the same way as potassium. However, available studies have not shown that the addition of phosphate to the treatment regimen leads to a more rapid recovery of bicarbonate, $\mathrm{pH}$ or glucose levels $(19,20)$.

\section{Hyperglycemic hyperosmolar state}

Features of HHS. HHS is characterized by marked hyperglycemia [blood glucose levels $>600 \mathrm{mg} / \mathrm{dl}(33.3 \mathrm{mmol} / \mathrm{l})$ ]; hyperosmolarity (plasma osmolarity $>320 \mathrm{mOsm} / \mathrm{kg}$ ) and dehydration; and the absence of ketoacidosis and depression of the sensorium (6).

The 2013 JBDS IP Group HHS definition includes (6): marked hyperglycemia [>540 mg/dl (30 mmol/l)]; no significant 
Table III. Markers of severity in HHS.

Variable

HHS

Marker of severity

Mental status

Oxygen saturation

Venous/arterial $\mathrm{pH}$

Potassium

Systolic blood pressure

Pulse

Urine output

Blood ketones

Bicarbonate level

Anion gap sodium

Osmolality

Miscellaneous

\author{
JBDS IP Group 2012 \\ GCS $<12$ or abnormal AVPU \\ $<92 \%$ on air (assuming normal baseline respiratory function) \\ $\mathrm{pH}<7.1$ \\ Hypokalemia $(<3.5 \mathrm{mmol} / \mathrm{l})$ or hyperkalemia $(>6 \mathrm{mmol} / \mathrm{l})$ \\ $<90 \mathrm{mmHg}$ \\ $>100$ or $<60 \mathrm{bpm}$ \\ $<0.5 \mathrm{ml} / \mathrm{kg} / \mathrm{h}$ or other evidence of acute kidney injury (AKI) \\ $>1 \mathrm{mmol} / \mathrm{l}$ \\ $\mathrm{mEq} / \mathrm{l}$ \\ $>160 \mathrm{mmol} / \mathrm{l}$ \\ $>350 \mathrm{mOsm} / \mathrm{kg}$ \\ Hypothermia \\ Acute or serious comorbidity (e.g., ACS, heart failure, or stroke)
}

Adapted from ref. 5. Equivalent to $>12 \mathrm{mEq} / \mathrm{l}$ for the USA anion gap calculation; the USA equation does not add [K+] to [Na+] prior to subtracting anions. HHS, hyperglycemic hyperosmolar state; GCS, Glasgow coma scale; AVPU, alert, voice, pain, unresponsive scale; bpm, beats per minute; AKI, acute kidney injury; ACS, acute coronary syndrome.

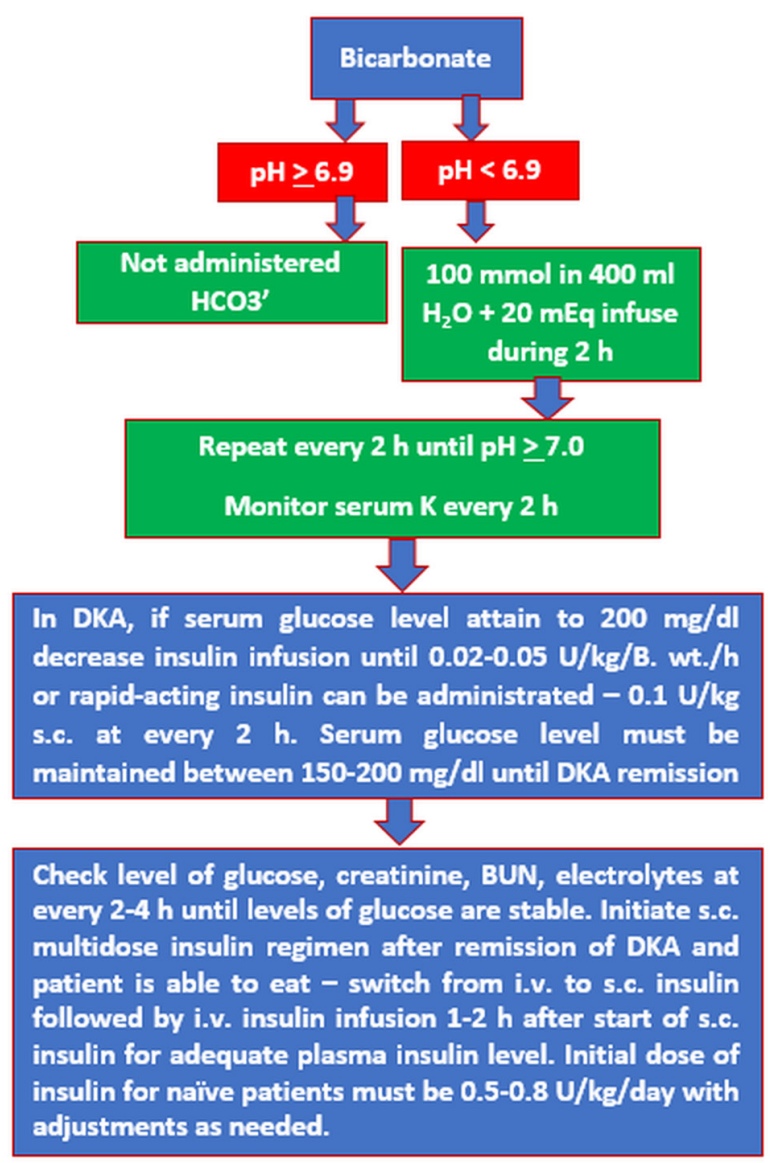

Figure 3. Management of bicarbonate and further steps in DKA treatment (adapted from refs. 11,21).

ketonemia (<3 mmol/l); no acidosis ( $\mathrm{pH}>7.3$; bicarbonate $>15 \mathrm{mmol} /$ ); hypovolemia; osmolality usually $>320 \mathrm{mOsm} / \mathrm{kg}$.
These guidelines also highlight that a mixed picture of HHS and DKA may occur. HHS is identified most frequently in individuals with type 2 diabetes; however, approximately $20 \%$ of cases have no history of this diagnosis. Markers by which the severity of HHS can be quantified are presented in Table III.

Management of HHS. The therapeutic management of HHS is different from DKA. Patients with HHS tend to be elderly with multiple complications and comorbidities $(1,2)$.

The main aims of HHS treatment include the gradual normalization of osmolality, replacement of fluid and electrolyte losses and normalization of blood glucose. In addition, as in the case of DKA, the trigger factor must be identified and addressed, arterial or venous thrombosis must be prevented, as well as potential complications (cerebral edema). The recommendations of the 2012 JBDS IP Group (6) can be followed in the management of HHS.

Osmolality can be measured or calculated using the formulae:

$[2 \mathrm{x} \mathrm{Na}(\mathrm{mEq} / \mathrm{l})+$ glucose $(\mathrm{mg} / \mathrm{dl})] / 18+\mathrm{BUN}(\mathrm{mg} / \mathrm{dl}) / 2.8$

or

$[2 \mathrm{x} \mathrm{Na}(\mathrm{mmol} / \mathrm{l})+$ glucose $(\mathrm{mmol} / \mathrm{l})+$ urea $(\mathrm{mmol} / \mathrm{l})]$

The aim of the initial therapy is expansion of the intra- and extravascular volume and to restore peripheral perfusion. As blood glucose drops, plasma osmolarity decreases and water moves into the intracellular space, resulting in increased serum sodium levels. This increase is not necessarily an indication of the administration of isotonic solutions. A decrease in plasma glucose at a rate of up to $90 \mathrm{mg} / \mathrm{dl} / \mathrm{h}$ is accompanied by an increase in serum sodium levels but also a decrease in osmolarity. In hypernatremic dehydration, $0.5 \mathrm{mmol} / \mathrm{l} / \mathrm{h}$ is the optimal rate of serum sodium depletion which is recommended. The rate of depletion of plasma sodium should not exceed $12 \mathrm{mmol} / \mathrm{l}$ per day. In the first $24 \mathrm{~h}$ it is indicated to replace approximately $50 \%$ of the estimated fluid losses, the rest being insured in the next $12 \mathrm{~h}(5)$. 


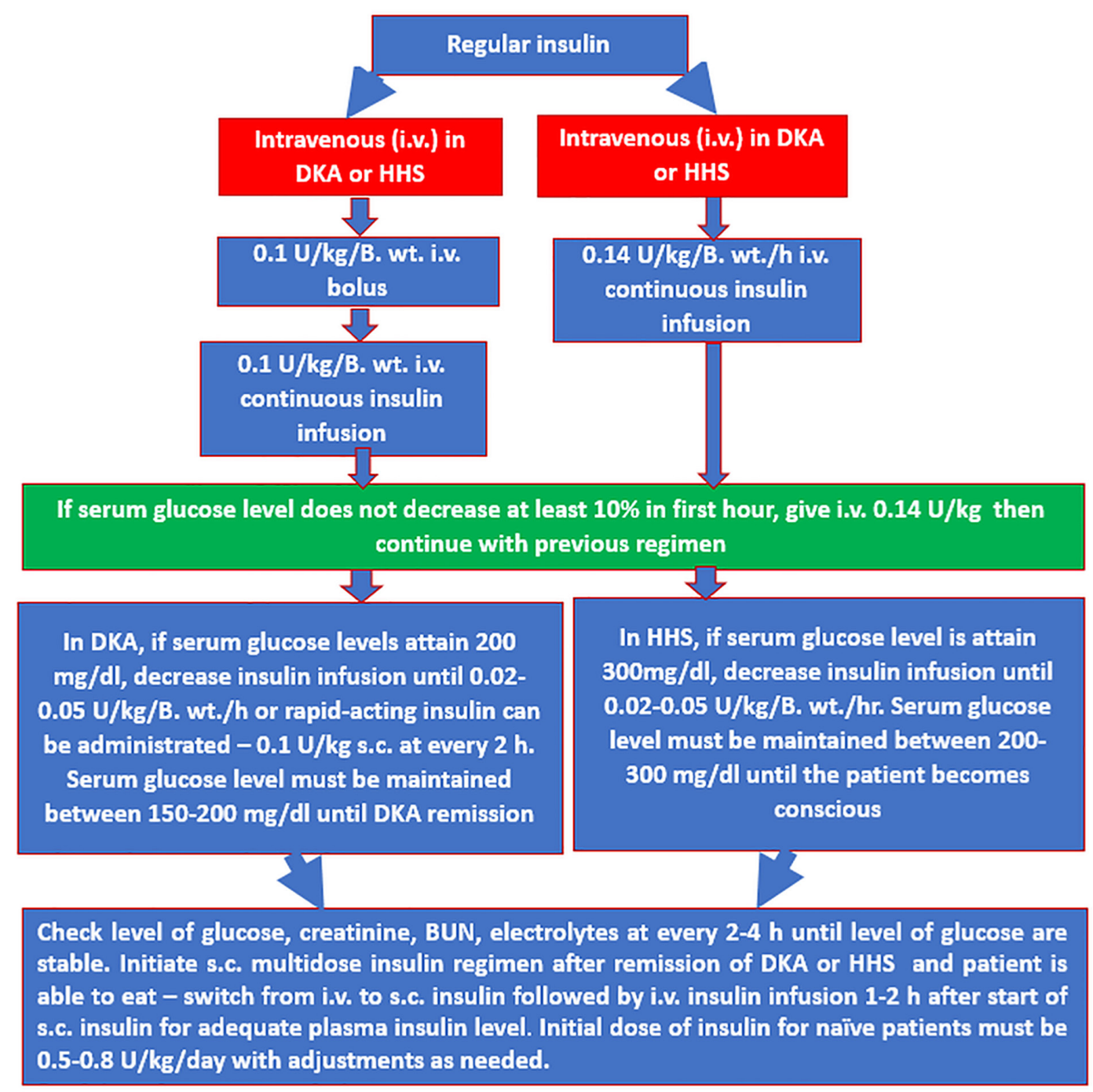

Figure 4. Insulin regimens in the management of DKA and HHS (adapted from refs. 5,11,21).

Significant ketonemia (PHBA $>1 \mathrm{mmol} / \mathrm{l})$ indicates relative hypoinsulinemia which requires initiation of insulin therapy. If significant ketonemia is not present (PHBA $<1 \mathrm{mmol} / \mathrm{l})$, insulin should not be started until the fluid deficit is corrected by administration of $0.9 \%$ sodium chloride which may lead to a decrease in blood glucose. Insulin administration prior to proper fluid replacement can lead to cardiovascular collapse, as water moves from the intravascular space, resulting in a decrease in intravascular volume. The recommended insulin dose is $0.05 \mathrm{U} / \mathrm{kg} / \mathrm{h}$. Lowering blood sugar by a rate of up to $90 \mathrm{mg} / \mathrm{dl} / \mathrm{h}$ is ideal (5).

In order to avoid hypoglycemia, a reasonable objective in the first $24 \mathrm{~h}$ is a blood glucose target of $180-270 \mathrm{mg} / \mathrm{dl}$. If the blood glucose falls $<250 \mathrm{mg} / \mathrm{dl}, 10 \%$ dextrose at $125 \mathrm{ml} / \mathrm{h}$ should commence, to be continued with the $0.9 \%$ sodium chloride solution (5).

In order to replace the potassium level, the indication is to proceed in the same way as in DKA. Complete normalization of electrolytes and osmolarity can take up to $72 \mathrm{~h}$. Due to the increased risk of arterial and venous thromboembolism, all the patients should receive low molecular weight prophylactic heparin (LMWH) $(21,22)$.

The 2009 ADA Hyperglycemic Crises Consensus and the JBDS IP Guidelines remain the predominant protocols of choice for the management of patients with DKA and HHS (Fig. 4).

\section{Hypoglycemia}

The annual prevalence of severe hypoglycemia is approximately $30 \%$ in individuals with type 1 diabetes (5). It is higher in those with risk factors including strict glycemic control, impaired awareness of hypoglycemia and increasing duration of diabetes (Table IV). It is also common during sleep, i.e., nocturnal hypoglycemia.

Clinical manifestations of hypoglycemia. The symptoms and signs of hypoglycemia are non-specific and can be classified into neuroglycopenic symptoms that are the direct result of lack of glucose in the brain and neurogenic or autonomic symptoms responsible for awareness of hypoglycemia (Table V) $(23,24)$.

Diagnosis. The diagnosis of hypoglycemia is based on three criteria (Whipple's triad): symptoms and signs suggestive of hypoglycemia (feeling faint, dizziness and sweating); low blood sugar levels during seizures $(<70 \mathrm{mg} / \mathrm{dl})$; and resolution of symptoms after glucose administration. 
Table IV. Risk factors for hypoglycemia.

Risk factors for adults

Tight glycemic control

Malabsorption

Injection into lipohypertrophy sites

Alcohol

Insulin prescription error (notable in hospitalized patients)

Long duration of diabetes

Renal dialysis

Drug interactions between hypoglycemic agents; e.g., quinine, selective serotonin reuptake inhibitors

Impaired renal function

Lack of anti-insulin hormone function; e.g., Addison's disease, hypothyroidism
Risk factors for children

Fasting or long duration of poor or nil intake

Inborn errors of metabolism (e.g., glycogen storage disorders) Insulinoma

Congenital or primary hyperinsulinism

Accidental ingestion of medications; e.g., salicylate, sulfonylureas, iron supplements, paracetamol

Poorly controlled diabetes mellitus in pregnancy is a risk for neonatal hypoglycemia

Sepsis is also a risk for neonatal hypoglycemia

Table V. Classification of symptoms and signs of hypoglycemia.

Neurogenic (or autonomic) symptoms

Neuroglycopenic

symptoms
Adrenergic symptoms

(catecholamine-mediated)
Cholinergic symptoms

(acetylcholine-mediated)

\section{Cognitive impairments}

Behavioral changes

Psychomotor abnormalities

Seizures

Coma
Sweating

Hunger

Paresthesia
Palpitations

Anxiety/arousal

Table VI. Management of hypoglycemia.

Initially

Glucose 10-20 g is given by mouth, either in liquid form or as granulated sugar (two teaspoons) or sugar lumps

Repeat capillary blood glucose after 10-15 min; if the patient is still hypoglycemic then the above can be repeated (probably up to 1-3 times)

If hypoglycemia causes unconsciousness, or the patient is uncooperative

Intravenous administration of $75-80 \mathrm{ml} 20 \%$ glucose or $150-160 \mathrm{ml}$ of $10 \%$ glucose (the volume will be determined by the clinical scenario)

Of note, $25 \mathrm{ml}$ of $50 \%$ glucose concentration is viscous, making it more irritant and more difficult to administer intravenously. It is rarely used now

Once the patient regains consciousness, oral glucose should be administered, as above

If the patient is at home, or intravenous (IV) access cannot be rapidly established

Glucagon $1 \mathrm{mg}$ should be given by intramuscular (IM), or subcutaneous (SC) injection

This dose is used in insulin-induced hypoglycemia (by SC, IM, or IV injection), in adults and in children $>8$ years (or body weight, $>25 \mathrm{~kg}$ )

1 unit of glucagon=1 mg of glucagon.

Management of hypoglycemia in adults. In case of hypoglycemia a quick-acting carbohydrate (sugar) should be administered followed by a longer-acting carbohydrate (toast, a normal meal) $(25,26)$.
The steps to be taken for the management of patients with hypoglycemia depend on the clinical condition and the environment where the patient is affected by diabetes mellitus (Table VI). 
If hypoglycemia is caused by an oral antidiabetic drug, the patient must be admitted to hospital, because the hypoglycemic effects of these drugs may persist for 12-24 h, and receive an ongoing glucose infusion.

If it is available, glucagon can also be administered subcutaneously (SC) or intramuscularly (IM). It has a relatively slow onset of action and relies on glycogen stores and thus, it may not be effective in cachectic patients, those with liver disease and in young children. It is contra-indicated in insulinoma and phaeochromocytoma. For inpatients, an infusion of $100 \mathrm{ml} / \mathrm{h}$ of $10 \%$ glucose may need to be considered (27).

Prolonged hypoglycemic coma. Prolonged hypoglycemic coma occurs due to cerebral edema and is defined by a duration of $>5 \mathrm{~h}$. In this case it is necessary to administer mannitol i.v. and dexamethasone with constant monitoring of glucose, and glucose i.v. to maintain the serum level at $90-180 \mathrm{mg} / \mathrm{dl}$ until consciousness has been restored, otherwise permanent brain damage can occur. If hypoglycemia has been caused by an overdose of insulin or sulfonylurea, $80 \mathrm{~g} / \mathrm{h}$ of $25-50 \%$ glucose may be required via a central line (25).

Treatment of hypoglycemia in children. Rapid treatment of hypoglycemia in children is crucial to prevent neurological damage. If the state of consciousness is maintained, the treatment is commenced by administering 10-20 g of glucose orally followed by the administration of fast carbohydrates in liquid form (milk $200 \mathrm{ml}$ ) or in solid form (2 teaspoons of sugar). If necessary, this can be repeated after 10-15 $\min (28,29)$.

Severe hypoglycemia, with unconscious state is an emergency as sugar cannot be administered orally; thus, the only solution is to inject glucagon (29-34). If glucagon is not effective within 10 min, administration of 33 or $10 \%$ glucose intravenously is required. After regaining consciousness, carbohydrates should be administered as soon as possible to restore liver glycogen.

Another possibility of treatment of hypoglycemia consists in the administration of octreotide in a bolus of $1-2 \mu \mathrm{g} / \mathrm{kg}$ every $6-8 \mathrm{~h}$ or in an infusion of $30 \mu \mathrm{g} / \mathrm{kg} / \mathrm{min}$. Glucagon is not effective in treating hypoglycemia due to fatty acid oxidation or glycogen storage disorders. It is also not indicated for the treatment of chronic hypoglycemia (29-34).

\section{Conclusions}

The current diagnostic and therapeutic approach to emergencies that occur in the evolution of diabetes is based on fairly well-developed guidelines and is consistent with scientific data known thus far regarding this condition. However, at present, the addressability of patients with acute complications of diabetes to EDs, especially those with diabetic coma, remains extremely high.

Most emergencies that occur in the evolution of diabetes and presented to the EDs have diabetes, ketoacidosis, hyperosmolar and hypoglycemic comas, all of which are life-threatening and with very high lethal potential. The therapeutic approach to coma in the ED may require intubation and ventilation of the patient, correction of acid-base and hydroelectrolytic imbalances, but especially correction of the level of serum blood glucose.
In addition to the correction of specific changes induced in addition to or without the glycemic level, the treatment of the causes that induce diabetic comas must be considered, especially in those with DKA or HHS. Currently the avoidance of these complications is based only on proper diet, stress avoidance, judicious treatment with numerous adjustments of oral antidiabetic doses or insulin doses which makes it considerably complicated for the contemporary world.

Despite recent discoveries in genetics and molecular medicine, no therapy or method has yet been found to allow the diabetic patient to lead a normal life in terms of diet and adaptability to daily stress and compliance to the therapeutic regime imposed by this condition.

\section{Acknowledgements}

Not applicable.

\section{Funding}

This work was supported by the dates obtained from the grant (research contract no. 26/40C/06.10.2021) with the research topic: Adult cardiovascular diseases in the context of acquired carbohydrate and lipid metabolic imbalances-from the silence of evolution to the drama of acute episodes in emergency units and compartments conducted by Maria Forțofoiu, as project director, in collaboration with the 'Didactica Association' and the University of Medicine and Pharmacy Craiova.

\section{Availability of data and materials}

All data generated or analyzed during this study are included in this published article.

\section{Authors' contributions}

MF, IMV, MCF, RP, DC, DR and VP contributed equally to the acquisition, analysis and systematization of data, manuscript writing and critical revision thereof for important intellectual content. All authors read and approved the final version of the manuscript. Data authentication is not applicable.

\section{Ethics approval and consent to participate}

Not applicable.

\section{Patients consent for publication}

Not applicable.

\section{Competing interests}

The authors declare that they have no competing interests.

\section{References}

1. Singh RK, Perros P and Frier BM: Hospital management of diabetic ketoacidosis: Are clinical guidelines implemented effectively? Diabet Med 14: 482-486, 1997.

2. Hardern RD and Quinn ND: Emergency management of diabetic ketoacidosis in adults. Emerg Med J 20: 210-213, 2003. 
3. Basu A, Close CF, Jenkins D, Krentz AJ, Nattrass M and Wright AD: Persisting mortality in diabetic ketoacidosis. Diabet Med 10: 282-284, 1993.

4. Kitabchi AE and Wall BM: Diabetic ketoacidosis. Med Clin North Am 79: 9-37, 1995.

5. American Diabetes Association (ADA): Hyperglycemic Crises Consensus Guidelines, 2009. https://care.diabetesjournals.org/ content/32/Supplement 1/S13. Access date: September 1, 2021.

6. Dhatariya K, Savage M, Claydon A, Dyer P, Evans P, Khan A, et al: Joint British Diabetes Societies (JBDS). Inpatient Care Group: The management of diabetic ketoacidosis in adults, Second edition, 2013. http://www.diabetologists-abcd.org. uk/JBDS/JBDS_IP_DKA_Adults_Revised.pdf. Access date: September 1, 2021.

7. Westerberg DP: Diabetic ketoacidosis: Evaluation and treatment Am Fam Physician 87: 337-346, 2013.

8. Umpierrez G and Korytkowski M: Diabetic emergenciesketoacidosis, hyperglycaemic hyperosmolar state and hypoglycaemia. Nat Rev Endocrinol 12: 222-232, 2016.

9. Yared Z and Chiasson JL: Ketoacidosis and the hyperosmolar hyperglycemic state in adult diabetic patients. Diagnosis and treatment. Minerva Med 94: 409-418, 2003.

10. Kitabchi AE and Nyenwe EA: Hyperglycemic crises in diabetes mellitus: Diabetic ketoacidosis and hyperglycemic hyperosmolar state. Endocrinol Metab Clin North Am 35: 725-751, 2006.

11. Kitabchi AE, Umpierrez GE, Miles JM and Fisher JN Hyperglycemic crises in adult patients with diabetes. Diabetes Care 32: 1335-1343, 2009.

12. Palmer BF and Clegg DJ: Electrolyte and acid-base disturbances in patients with diabetes mellitus. N Engl J Med 373: 548-559, 2015.

13. Grigorescu ED, Lăcătușu CM, Crețu I, Floria M, Onofriescu A, Ceasovschih A, Mihai BM and Sorodoc L: Self-reported satisfaction to treatment, quality of life and general health of type 2 diabetes patients with inadequate glycemic control from North-Eastern Romania. Int J Environ Res Public Health 18: $3249,2021$.

14. Kamel KS and Halperin ML: Acid-base problems in diabetic ketoacidosis. N Engl J Med 372: 1969-1970, 2015.

15. Magder S and Emami A: Practical approach to physical-chemical acid-base management. Stewart at the bedside. Ann Am Thorac Soc 12: 111-117, 2015.

16. Seifter JL: Integration of acid-base and electrolyte disorders. N Engl J Med 371: 1821-1831, 2014.

17. Story DA and Kellum JA: New aspects of acid-base balance in intensive care. Curr Opin Anaesthesiol 17: 119-123, 2004.

18. Schiraldi F and Guiotto G: Base excess, strong ion difference, and expected compensations: As simple as it is. Eur J Emerg Med 21: 403-408, 2014

19. Fisher JN and Kitabchi AE: A randomized study of phosphate therapy in the treatment of diabetic ketoacidosis. J Clin Endocrinol Metab 57: 177-180, 1983.

20. Wilson HK, Keuer SP, Lea AS, Boyd AE III and Eknoyan G: Phosphate therapy in diabetic ketoacidosis. Arch Intern Med 142: 517-520, 1982
21. Fayfman M, Pasquel FJ and Umpierrez GE: Management of hyperglycemic crises: Diabetic ketoacidosis and hyperglycemic hyperosmolar state. Med Clin North Am 101: 587-606, 2017.

22. American Diabetes Association: Hospital admission guidelines for diabetes (Position Statement). Diabetes Care 27 (Suppl 1): S103, 2004.

23. Tomky D: Detection, prevention, and treatment of hypoglycemia in the hospital. Diabetes Spectrum 18: 39-44, 2005.

24. Greenhalgh T: Oxford Textbook of Medicine. 4th edition. Warrell DA, Cox TM, Firth JD and Benz Jr EJ (eds). Family Practice 20, Oxford University Press, Oxford, 2003.

25. Walden E, Stanisstreet D, Graveling A, et al: Joint British Diabetes Societies: The hospital management of hypoglycaemia in adults with diabetes mellitus. Third edition. Diabetes UK, 2013. https:// www.diabetes.org.uk/professionals/position-statements-reports/ specialist-care-for-children-and-adults-and-complications/thehospital-management-of-hypoglycaemia-in-adults-with-diabetes-mellitus. Access date: September 1,2021.

26. Achoki R, Opiyo N and English M: Mini-review: Management of hypoglycaemia in children aged 0-59 months. J Trop Pediatr 56: 227-234, 2010

27. Frier BM: How hypoglycaemia can affect the life of a person with diabetes. Diabetes Metab Res Rev 24: 87-92, 2008.

28. Pearson T: Glucagon as a treatment of severe hypoglycemia: Safe and efficacious but underutilized. Diabetes Educ 34: 128-134, 2008.

29. International Diabetes Federation: IDF Diabetes Atlas. 9th edition. International Diabetes Federation, Belgium, 2019. https://diabetesatlas.org/atlas/ninth-edition/. Access date: September 1, 2021.

30. Chen YT, Tan YZ, Cheen M and Wee HL: Patient-reported outcome measures in registry-based studies of type 2 diabetes mellitus: A systematic review. Curr Diabetes Rep 19: 135, 2019.

31. Grigorescu E, Sorodoc V, Floria M, Anisie E, Popa AD, Onofriescu A, Ceasovschih A and Sorodoc L: The inflammatory marker HSCRP as a predictor of increased insulin resistance in type 2 diabetics without atherosclerotic manifestations. Rev Chim (Bucharest) 70: 1791-1794, 2019.

32. Trikkalinou A, Papazafiropoulou AK and Melidonis A: Type 2 diabetes and quality of life. World J Diabetes 8: 120-129, 2017.

33. Palamenghi L, Carlucci MM and Graffigna G: Measuring the quality of life in diabetic patients: A scoping review. J Diabetes Res 2020: 5419298, 2020.

34. Speight J, Holmes-Truscott E, Hendrieckx C, Skovlund S and Cooke D: Assessing the impact of diabetes on quality of life: What have the past 25 years taught us? Diabet Med 37: 483-492, 2020.

This work is licensed under a Creative Commons Attribution-NonCommercial-NoDerivatives 4.0 International (CC BY-NC-ND 4.0) License. 